\title{
Gas Injection Optimization to Increase Oil Production at MRA PT. PHE ONWJ
}

\author{
Harry Budiharjo Sulistyarso ${ }^{1 *}$, KRT Nur Suhascaryo ${ }^{1)}$ Mochamad Jalal Abdul Goni ${ }^{1)}$ \\ 1) Petroleum Engineering, Pembangunan Nasional Veteran University, Yogyakarta \\ *corresponding e-mail: harry_hb@upnyk.ac.id
}

\begin{abstract}
The MRA platform is one of the offshore platforms located in the north of the Java Sea. The MRA platform has 4 production wells, namely MRA-2ST, MRA-4ST, MRA-5, and MRA-6 wells. The 4 production wells are produced using an artificial lift. The limited gas injection at the MRA Platform at 3.1 MMSCFD makes the production of wells at the MRA Platform not optimal because the wells in the MRA Platform are experiencing insufficient gas injection. The production optimization method in this study is how to determine the optimum gas injection for each well with the limited number of gas available, and how to keep the gas injection entering the well constant. The results of the analysis that the optimum gas injection for the MRA-2ST well is 0.5552 MMSCFD, the MRA-6 well is 1.0445 MMSCFD, the MRA-5 well is 0.7657 MMSCFD \& MRA-4ST is 0.7346 MMSCFD. The manual gas lift valve in the MRA-4ST is also replaced with automatic gas lift valve to ensure that the gas injection for each well can be kept constant. The redistribution of gas injection carried out by the author has increased the total production rate of the MRA Platform by 11,160 Barrel Oil/year.
\end{abstract}

Keywords: gas lift; insufficient; optimization

\section{INTRODUCTION}

(Khamehchi, 2017) The gas lift method uses the gas injection method. The gas is injected through the annulus then the gas enters the tubing through the GLV and mixes with the hydrocarbon fluid. This condition will cause a decrease in the pressure gradient, causing the pressure loss along the tubing to be smaller. When the pressure loss along the tubing becomes smaller, causing an increase in the WHP value, this will result in hydrocarbon fluids being produced until the separation equipment is on the surface of the separator. The most widely used method for gas injection allocation is the Equal Slope optimization method. The search for alternative methods for injection gas allocation is needed to obtain a gas allocation method that is easy and can be applied succinctly.

(Rahma, 2013) In the process of producing hydrocarbon fluids, the gas lift method is usually applied to several field clusters. In one field cluster, gas is usually injected through an injection manifold. The produced fluid will be flowed to the production separator using a flowline to separate the gas and liquid fluids. The separated gas will be flowed back for the injection process, while the separated liquid will flow into the tank through the oil distribution pipe. Such a system is known as a multiwell gas lift system. Wells that can produce higher oil for a certain injection value will be more likely to be allocated more gas injection to obtain maximum total oil production. The increase in the rate of oil production will take place along with the increase in the rate of gas injection. However, a gas injection rate that is too high can cause a slippage effect where the gas will move faster than the fluid so that the rate of oil production will decrease. This occurs when the gas injection rate has passed the optimum limit.

(Mayhill, 1974) Evaluation and optimization of the gas lift well production begin with evaluating the gas lift performance curve as the basis for the gas injection optimization method. The gas lift performance curve is a curve that describes the well's reaction to the gas injection rate that is injected into the well. Excessive gas injection rate will cause a slippage effect where the gas phase will move faster than the liquid phase. This will lead to reduced profitability even to a decrease in production. After the curve passes the maximum injection condition, the curve will show a decrease which indicates that the gas injection rate has been excessive, resulting in a gas slippage effect. Excessive gas injection rate will cause a slippage effect where the gas phase will move faster than the liquid phase.

(Ricky, 2016) The development of the quadratic equation of the second-order polynomial is to allocate the total injection gas that is as optimal as possible in each of the existing continuous gas lift wells with a method that is applied back wise method with backward calculation. The rate of gas injected into the well (n-1) is the remaining gas injected into the well (n) so that it can be directly determined how much gas is allocated for (n-1), as a function of the rate of gas injection injected into the well (n). -1), so on until the total injection gas is injected into the last well. Gas allocation for a given number of wells in a single multiwell continuous gas lift system can be determined directly. The Ricky Model was 
prepared to simplify the Equal Slope Optimization method, so that the optimum allocation of injection gas for all wells can be obtained directly and easily without doing iterations in the form of trial scenarios or graphical methods. The calculation begins by applying the first partial derivative of the total production function (y). In the total production function (y) two variables build the function, namely the gas allocation variable $(\mathrm{x})$ and the total gas injection variable (z). It is said that the total production function (y) is partially reduced to the gas allocation variable (x) because the total production function $(\mathrm{y})$ is only derived from the gas allocation variable $(\mathrm{x})$, while the total injection gas variable $(\mathrm{z})$ is considered constant. By applying the first partial derivative to total production as a function of allocation and total injection gas, the optimum allocation for each well will be obtained as a function of total gas injection.

From the research references described above, the Ricky Model is chosen because it is one of the methods that can determine the optimum gas injection rate with the amount of gas injection available, the manual gas lift valve in the MRA4ST is also replaced based on an economic feasibility analysis to ensure that gas injection for each well can be kept constant.

\section{METHODS}

(Ricky, 2016) Simplifies the Gomez equation (Gomez, 1974) in the form of a mathematical equation as follows:

$\mathbf{Q}_{1}=\mathbf{a} \mathbf{Q g}^{2}+\mathbf{b} \mathbf{Q g}_{\mathrm{g}}+\mathbf{c}$

It is known that the quadratic equation of a second-order polynomial developed by Gomez from GLPC Mayhill is as follows:

$\mathbf{y}=a x^{2}+b x+c$

If it is known that there are two gas lift wells. So, the quadratic polynomial for each of the gas lift wells becomes:

$\mathrm{y}_{1}=a_{1} x_{1}^{2}+b_{1} x_{1}+c_{1}$

$\mathrm{y} 2=a_{2} x_{2}^{2}+b_{2} x_{2}+c 2$

Given the oil production in each well, the equation for total oil production is as follows:

$$
\mathrm{y} 12=a_{1} x_{1}^{2}+a_{2} x_{2}^{2}+b_{1} x_{1}+b_{2} x_{2}+c_{1}+c_{2}
$$

Where the total injection gas injected into the two gas lift wells is as follows:

$\mathrm{Z}_{2}=x_{1}+x_{2}$

$x_{1}=Z_{2}-x_{2}$

Equation (5) is a constraint in the study for two gas lift wells, with this equation, the amount of gas allocation for wells 1 and 2 should not exceed the predetermined total gas injection value. Substitute equation (7) into equation (5) so that it becomes:

$y_{12}=a_{1}\left(Z_{2}-x_{2}\right)^{2}+a_{2} x_{2}^{2}+b_{1}\left(Z_{2}-x_{2}\right)+b_{2} x_{2}+c_{1}+c_{2}$

Group the $\boldsymbol{x}$ variable in equation (8) so that it turns into:

$y_{12}=a_{1}\left(Z_{2}-x_{2}\right)^{2}+a_{2} x_{2}^{2}+b_{1} Z_{2}-\left(b_{1}+b_{2}\right) x_{2}+c_{1}+c_{2}$

To determine the position of the point value until the total production value ( $\left.\mathrm{y}_{12}\right)$ reaches a stationary turning point (change in liquid flow rate $=0$ ) by using the first partial derivative of equation (9) to gas allocation $(\boldsymbol{x} \mathbf{2})=0$ with $=$ constant, then analyze the equation :

$\frac{d y_{12}}{d x_{2}}=2 \boldsymbol{a}_{1}\left(\boldsymbol{Z}_{2}-\boldsymbol{x}_{2}\right)(-1)+2 \boldsymbol{a}_{2} \boldsymbol{x}_{2}+0+\left(\boldsymbol{b}_{2}-\boldsymbol{b}_{1}\right)+0+0$

Based on equation (10), the equation for the injection gas allocation in the second well is as follows:

$\boldsymbol{x}_{2}=\frac{1}{\left(a_{1}+a_{2}\right)}\left(\left(a_{1} Z_{2}+\frac{1}{2}\left(b_{1}-b_{2}\right)\right)\right.$ 
Then in the application for the system of 3 (three) and 4 (four) wells, the basic method used is the same as the previous two wells, and so on:

$x_{3}\left(\mathrm{Z}_{3}\right)=\frac{\mathrm{Z}_{3} a_{1} a_{2}+\frac{1}{2}\left(a_{2}\left(b 1-b_{3}\right)+a_{1}\left(b_{2}-b_{3}\right)\right)}{\left(a_{1} a_{2}+a_{1} a_{3}+a_{2} a_{3}\right)}$

Based on the above formula, it can be concluded that for the application of more than 4 wells, the basic method used is the same as the previous two wells, and so on:

$x_{\mathrm{n}}(\mathrm{Zn})=\frac{1}{\sum_{i=1}^{n}\left[\frac{\prod_{j=1}^{n} a_{j}}{a_{i}}\right]}\left[\mathrm{Z}_{\mathrm{n}}\left(\prod_{i=1}^{n-1} a_{i}\right)+\frac{1}{2} \sum_{i=1}^{n-1}\left[\frac{b_{i}-b_{n}}{a_{i}}\left(\prod_{j=1}^{n-1} a_{j}\right)\right]\right.$

To keep the gas injection flow rate of a well constant, an automatic control valve is needed. Production wells that use gas injection as an artificial lift, the control valve function is very important because the control valve function is to regulate the amount and pressure of gas injection that enters the casing. Installation of an automatic control valve is evaluated economically to ensure project feasibility. An economic evaluation of a project can be done with several parameters, namely: Pay Out Time (POT) \& \% Rate of Return (ROR):

Pay Out Time is used to measure the ability to return project investment funds (in years). For industrial petroleum, it ranges from 5 to 10 years. It is hoped that the POT price will be as small as possible because the smaller it is, the more profitable it is to implement:

$P O T=\frac{\text { Fixed Capital Investment }}{\text { Profit after tax }}$

Rate of Return is the comparison of profit after tax with Fixed Capital Investment (fixed capital investment) within a certain age period of the designed equipment.

$R O R=\frac{\text { Profit }}{\text { Fixed Capital }} \times 100 \%$

\section{RESULTS AND DISCUSSION}

Determination of the optimal gas injection allocation is very dependent on the existing water cut data in each well. The priority is based on the lower well water cut value which will get the maximum gas allocation. The water cut data from the field shows the water cut off the MRA-2ST, MRA-4ST, MRA-5, and MRA-6 wells as follows:

Table 1. Water Cut MRA Well
\begin{tabular}{|c|c|c|}
\hline No & Well & WC $\%$ \\
\hline 1 & MRA-2ST & 13 \\
\hline 2 & MRA-4ST & 92 \\
\hline 3 & MRA-5 & 45 \\
\hline 4 & MRA-6 & 25 \\
\hline
\end{tabular}

Based on the GLPC graph of the MRA-2ST well Figure 1. the quadratic polynomial formula $y=-35258 \times 2+40001 \mathrm{x}-$ 11153 with a value of $\mathrm{R}^{2}=0.9511$. 


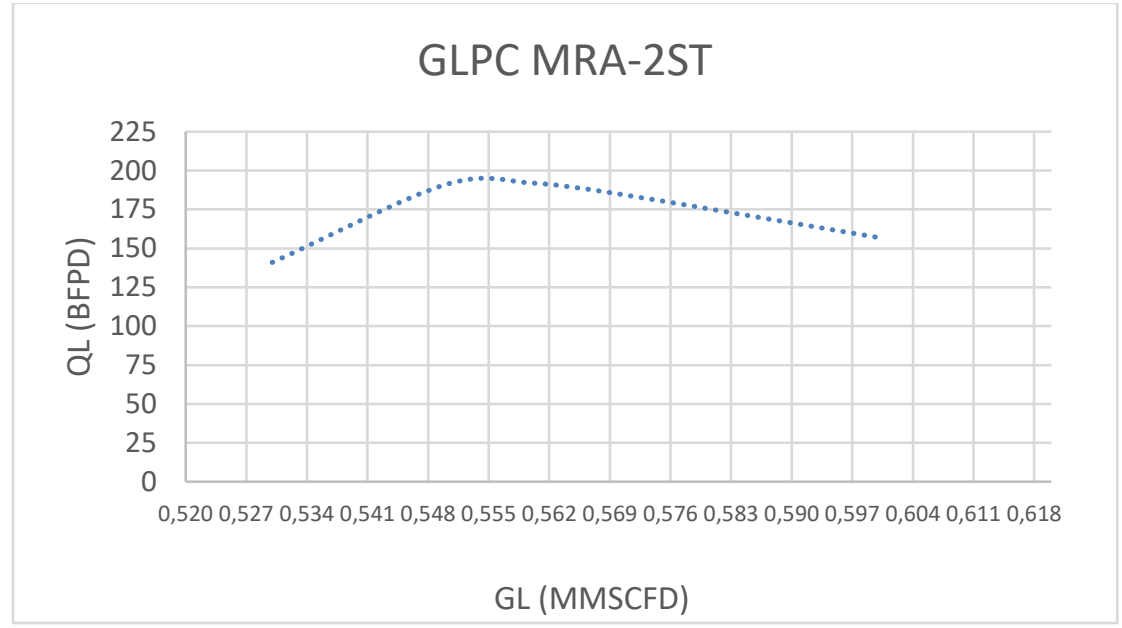

Figure 1. GLPC MRA-2ST Well

Based on the GLPC of the MRA-6 well, which can be seen in Figure 2. the quadratic polynomial formula for the graph above is $y=-3836.5 \times 2+8980.5 x-4757.6$ and the value of $R^{2}=0.9539$.

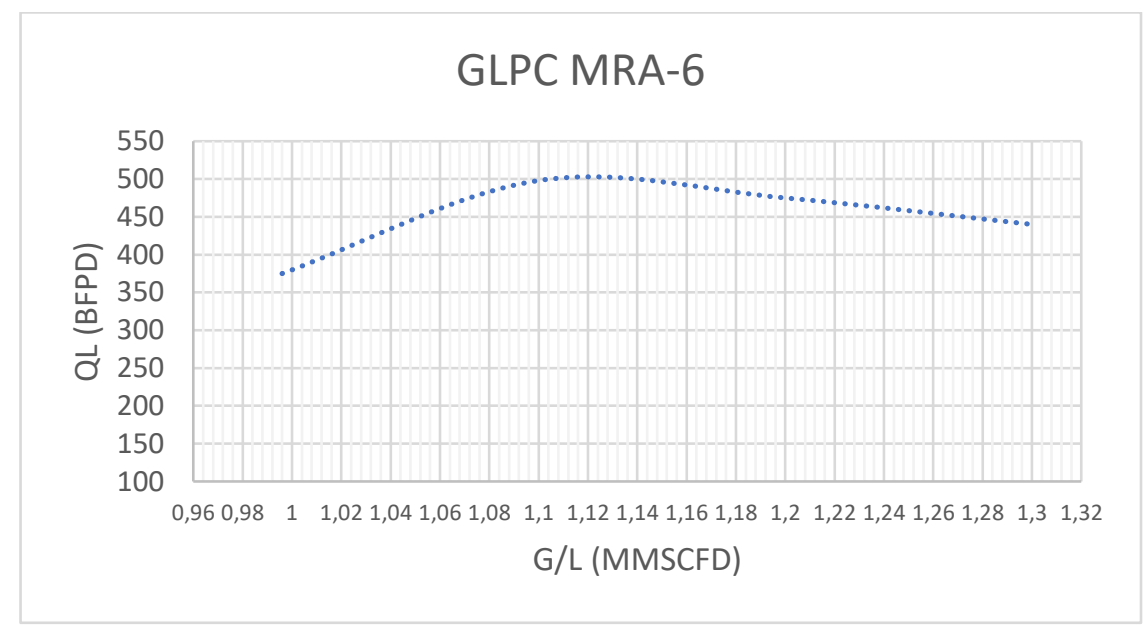

Figure 2. GLPC MRA-6 Well

Based on the GLPC graph reconstruction of the MRA-5 well Figure 3. the quadratic polynomial formula $y=-5186.3 \times 2$ $+8653.5 \mathrm{x}-3356.7$ with $\mathrm{R}^{2}=0.9586$ was obtained.

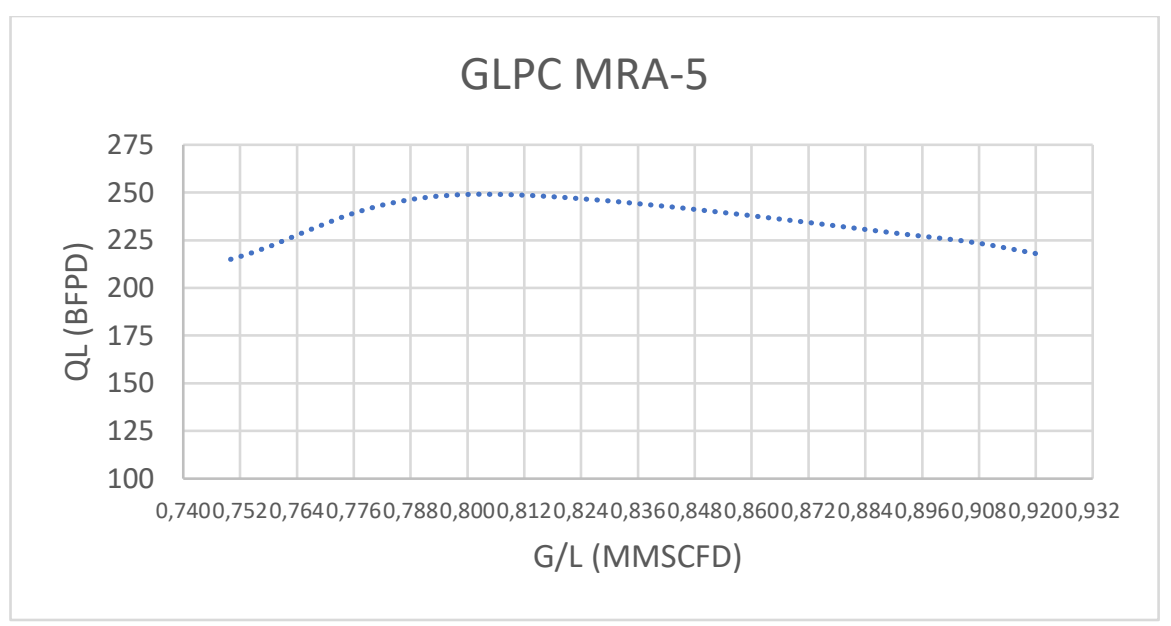




\section{Figure 3. GLPC MRA-5 Well}

Based on the reconstruction of the MRA-4ST well GLPC can be seen in Figure 4. the quadratic polynomial formula for the graph above is $y=-42181 x 2+62682 x-22866$ and the value of $R^{2}=0.9525$.

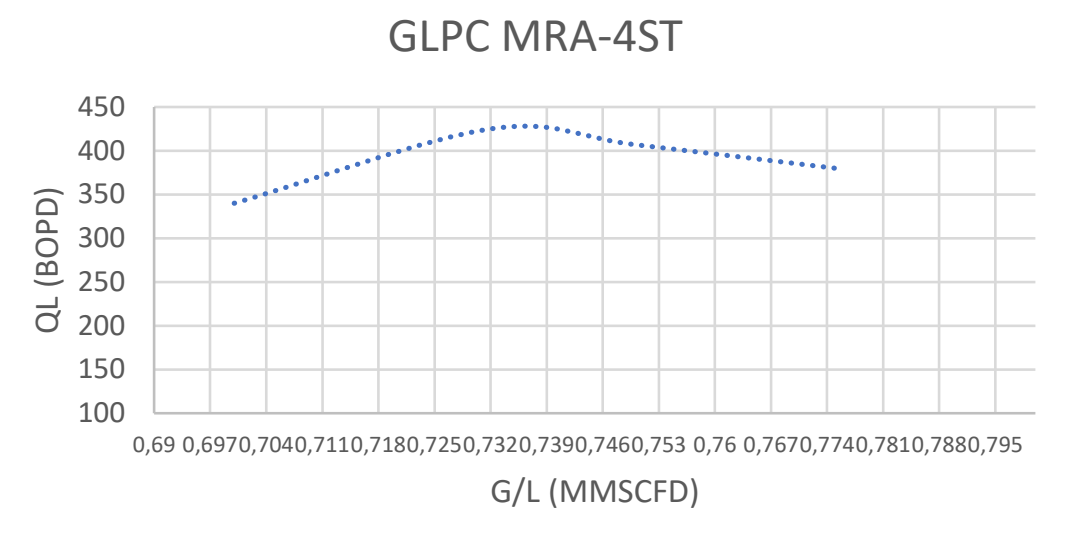

Figure 4. GLPC MRA-4ST Well

Use equation 13 The following are recommendations for optimum gas injection according to Ricky Model:

Table 2. Gas Injection Recommendation for MRA Well

\begin{tabular}{|c|c|c|}
\hline Well & WC, \% & Qg inj actual, MMSCFD \\
\hline MRA-2ST & 13 & 0.5552 \\
\hline MRA-6 & 25 & 1.0445 \\
\hline MRA-5 & 45 & 0.7657 \\
\hline MRA-4ST & 92 & 0.7346 \\
\hline \multicolumn{2}{|c|}{ Total } & 3.1000 \\
\hline
\end{tabular}

Based on the gas allocation that has been determined using the Ricky Model and also the water cut priority, it is concluded that the MRA-2ST well is the well with the maximum gas injection distribution based on the Ricky Model, which is 0.5552 MMSCFD. After knowing the gas allocation based on distribution priorities, then determining the oil flow rate or oil recovery that can be obtained based on gas injection optimization. The following are the results of oil recovery based on polynomial data for each well:

Table 3. Oil Produce of MRA Wells

\begin{tabular}{|c|c|c|c|c|c|c|}
\hline \multirow{2}{*}{ Well } & \multirow{2}{*}{$\begin{array}{c}\text { WC, } \\
\%\end{array}$} & $\begin{array}{c}\text { Qg inj actual, } \\
\text { MMSCFD }\end{array}$ & $\begin{array}{c}\text { Qo actual, } \\
\text { BOPD }\end{array}$ & Qg inj Ricky Model & \multicolumn{2}{c|}{ Qo @ Ricky Model } \\
\cline { 5 - 7 } & & & MMSCFD & BFPD & BOPD \\
\hline MRA-2ST & 13 & 0.4500 & 107 & 0.5552 & 187.3811 & 163.0215 \\
\hline MRA-6 & 25 & 1.098 & 330 & 1.0445 & 436.9865 & 327.7399 \\
\hline MRA-5 & 45 & 0.7980 & 151 & 0.7657 & 228.5755 & 125.7165 \\
\hline MRA-4ST & 92 & 0.7500 & 30 & 0.7346 & 417.7622 & 33.421 \\
\hline \multicolumn{2}{r|r}{ Total } & 3.100 & 618 & 3.100 & 1270.7052 & 649.8989 \\
\hline
\end{tabular}

To keep the gas injection constant, it is necessary to install an automatic control valve on MRA-4ST well. Economic calculations need to be carried out to support manual gas lift valve replacement. With the price of oil per barrel of USD 70 , the monthly profit can be calculated as follows:

$$
\begin{aligned}
\text { Profit } & =930 \mathrm{BO} / \text { Month } \times 12 \times \text { USD } 70 \\
& =781,200 \text { USD/year }
\end{aligned}
$$


The Automatic Control valve price of USD 29,000 is included in the installation cost. Based on equations 14 and 15, POT and ROR values of the automatic control valve installation project are POT 0.04 year \& ROR $24.3 \%$.

\section{CONCLUSION}

From the calculation and prioritization results, the MRA-2ST well is the priority well because it has a water cut of $13 \%$ with gas injection of 0.552 MMSCFD. The second priority is the MRA-6 well which has a water cut of 25\%, the MRA6 well has the optimum gas injection value of 1.0445 MMSCFD. The third priority is the MRA-5 well which has a water cut of $45 \%$ with an optimum gas injection recommendation of 0.7657 MMSCFD. Finally, the MRA-4ST well has a water cut of $92 \%$ with an optimum gas injection of 0.7346 . The results of calculations using the latest gas injection recommendations obtained an increase in total oil production for the MRA Platform by 930 Barrel Fluid/month. The installation of a smart control valve on the MRA-4ST well managed to maintain gas injection of 0.7346 . Installing Automatic Control Valve on the MRA-4ST well to keep the gas injection costing USD 29,000. The ROR of the Smart Control Valve installation project is $24.3 \%$ and the POT is 0.04 years.

\section{REFERENCES}

Buitrago, M., et al. 2016. Designing Construction Processes in Buildings by Heuristic Optimization. Engineering Structures, 111, 1-10.

Camponogara, E., \& de Conto, A. M. 2005. Gas-Lift Allocation Under Precedence Constraints: Piecewise-Linear Formulation and K- Covers. In Proceedings of the 44th IEEE Conference on Decision and Control (pp. 4422 4427). IEEE.

Camponogara, E., \& Nakashima, P. H. R. 2006. Solving a Gas-Lift Optimization Problem by Dynamic Programming. European Journal of Operational Research 174(2), 1220-1246.

Christensen, J., and Bastien, C. 2016. Nonlinear Optimization of Vehicle Safety Structures. Amsterdam. Elsevier.

de Souza, J. N. M. N. M., et al. 2010. Modeling, Simulation and Optimization of Continuous Gas Lift Systems for Deepwater Offshore Petroleum Production. Journal of Petroleum Science and Engineering, 72(3), 277-289.

Edwards, R., Marshall, D. L., \& Wade, K. C. 1990. A Gas-Lift Optimization and Allocation Model for Manifolded Subsea Wells. In European Petroleum Conference. Society of Petroleum Engineers.

Eni P. Kanu, Joe Mach, Kermit E. Brown. 1982. Economic Approach to Oil Production and Gas Allocation in Continuous Gas Lift. J. Pet. Tech, February 1982, pp. 1886-1892.

Fletcher, R. 2013. Practical Methods of Optimization, Second Edition- Fletcher-Wiley Online Library. New York.Wiley. Gomez, V. 1974. Optimization of Continuous Flow Gas Lift Systems. M. S. Thesis, U. of Tulsa.

Guo, B., Lyons, W. C., and Ghalambor, A. 2007. Petroleum Production Engineering A Computer-Assisted Approach. Gulf Professional Pub.

Guyaguler, B., \& Byer, T. J. 2008. A New Rate-Allocation-Optimization Framework. SPE Production \& Operations, 23(04), 448-457.

Iqbal, K. 2013. Fundamental Engineering Optimization Methods. ISBN 978- 87-403-0489-3. 1st edition.

Jacoud, A., et al. 2015. Modeling and Extremum Seeking Control of Gas Lifted Oil Wells. IFAC-PapersOnLine, 48(2012), 21-26.

James F Lea, Henry V Nickens. 1999. Selection of Artificial Lift. Paper SPE 52157 Presented at the SPE Mid-Continent Operations Symposiums. Oklahoma City. Oklahoma. March 28-31, 1999.

Kermit E Brown. 1984. The Technology of Artificial Lift Methods Volume 2a. The University of Tulsa.

Khamehchi, E., et al. 2009. Continuous Gas Lift Optimization with a Novel Genetic Algorithm. Australian Journal of Basic and Applied Sciences, I(4), 587-594.

Khamehchi, Ehsan., Mohammad Reza Mahdiani. 2017. Gas Allocation Optimization Methods in Artificial Gas Lift.

Khishvand, M., Khamehchi, E., \& Nokandeh, N. R. 2015. A Nonlinear Programming Approach to Gas Lift Allocation Optimization. Energy Sources, Part A: Recovery, Utilization, and Environmental Effects, 37(5), 453-461. 
Lima Silva, T., et al. 2015. Modeling of Flow Splitting for Production Optimization in Offshore Gas Lifted Oil Fileds: Simulation Validation and Applications. Journal of Petroleum Science and Engineering, 128, 86-97.

Lo, K. K. 1992. Optimum Lift-Gas Allocations Under Multiple Production Constraints.

Luenberger, D. G. 1984. Linear and Non-Linear Programming. New York. Addison-Wesley.

Mayhill, T. D. 1974. Simplified Method for Gas Lift Well Problem Identification and Diagnosis: Paper SPE 5151 Presented at the SPE 49th Annual Fall Meeting, Houston, TX, Oct 6-9, 1974.

Muchibbus, Farasdaq. 2019. Achieving Exceptional Efficiency of Gas Lift Design in Offshore North West Java Field Using Dynamic, Time-Based Equalised Method. Paper SPE 196534 MS Presented at the SPE/IATMI Asia Pacific Oil and Gas Conference and Exhibition held in Bali, Indonesia, Oct 29-31, 2019.

Nishikiori, N., et al. 1989. An Improved Method for Gas Lift Allocation Optimization. In SPE Annual Technical Conference and Exhibition. Society of Petroleum Engineers.

Nguyen, Tan. 2020. Artificial Lift Methods: Design, Practices, and Applications. Springer.

Peter, Max S. and Klaus D. Timmerhaus, 2003, "Plant Design \& Economic. for Chemical Engineers", 5th Edition, Mc. Grow Hill Book Company: New York.

Rahma, Ulfia. 2013. Optimisasi Alokasi Gas Injeksi Pada Sistem Multiwell Gas Lift. Skripsi ITB.

Rao, S. S., and Rao, S. S. 2009. Engineering optimization: Theory and practice. John Wiley and Sons.

Ricky Aditiya Fandi et al. 2017. A Simple-Effective-Efficient. Analytical Model for Multiwell Gas Lift Allocation Optimization. IPA. Indonesian Petroleum Association. May. IPA17-468-E.

Shen, Z., el al. (2013). Artificial Lift Technique of Multistage Sliding Vane Pump Used in Thermal Production Well. Petroleum Exploration and Development, 40(5), 651-655.

Simmons, W. E. 1972. Optimizing Continuous Flow Gas Lift Wells. Pet. Eng. Intl. (Aug 1972) 46-48 and (Sept 1972) 68-72.

Stanghelle, K. U. 2009. Evaluation of artificial lift methods on the Gyda field. Norway. University of Stavanger. , API, 1994. Gas Lift Book 6 of The Vocational Training Series Third Edition. The API Exploration and Production Department. , Mike-Mike F/S, 2021. Well Test Reading parameter. 01 - 30 Aug. 